$1-2020$

\title{
Potential physical impacts of sea-level rise on the Pearl River Estuary, China
}

Bo Hong

Zhonghui Liu

Jian Shen

Virginia Institute of Marine Science

Hui Wu

Wenping Gong

See next page for additional authors

Follow this and additional works at: https://scholarworks.wm.edu/vimsarticles

Part of the Oceanography Commons

\section{Recommended Citation}

Hong, Bo; Liu, Zhonghui; Shen, Jian; Wu, Hui; Gong, Wenping; Xu, Hongzhou; and Wang, Dongxiao, "Potential physical impacts of sea-level rise on the Pearl River Estuary, China" (2020). VIMS Articles. 1819. https://scholarworks.wm.edu/vimsarticles/1819

This Article is brought to you for free and open access by the Virginia Institute of Marine Science at W\&M ScholarWorks. It has been accepted for inclusion in VIMS Articles by an authorized administrator of W\&M ScholarWorks. For more information, please contact scholarworks@wm.edu. 
Authors

Bo Hong, Zhonghui Liu, Jian Shen, Hui Wu, Wenping Gong, Hongzhou Xu, and Dongxiao Wang 


\title{
Potential physical impacts of sea-level rise on the Pearl River Estuary, China
}

\author{
Bo Hong ${ }^{\mathrm{a}, \mathrm{c}, *}$, Zhonghui $\mathrm{Liu}^{\mathrm{a}}$, Jian Shen ${ }^{\mathrm{b}}$, Hui $\mathrm{Wu}^{\mathrm{c}}$, Wenping Gong ${ }^{\mathrm{d}}$, Hongzhou $\mathrm{Xu}^{\mathrm{e}}$, \\ Dongxiao Wang ${ }^{f}$ \\ ${ }^{a}$ School of Civil and Transportation Engineering, South China University of Technology, Wushan RD., Tianhe District, Guangzhou 510641, China \\ ${ }^{\mathrm{b}}$ Virginia Institute of Marine Science, William \& Mary, P.O. Box 1346, Gloucester Point, VA 23062, USA \\ ${ }^{\mathrm{c}}$ State Key Laboratory of Estuarine and Coastal Research, East China Normal University, 3663 Zhongshan Rd. N., Shanghai 200062, China \\ ${ }^{\mathrm{d}}$ School of Marine Sciences, Sun Yat-Sen University, 135 Xingangxi Rd., Guangzhou 510275, China \\ ${ }^{\mathrm{e}}$ Institute of Deep-Sea Science and Engineering, Chinese Academy of Sciences, Luhuitou RD., Sanya 572000, China \\ ${ }^{\mathrm{f}}$ State Key Laboratory of Tropical Oceanography, South China Sea Institute of Oceanology, Chinese Academy of Science, Guangzhou 510301, China
}

\section{A R T I C L E I N F O}

\section{Keywords:}

Sea-level rise

The Pearl River Estuary

Numerical model

Salinity

Transport process

Time scale

\begin{abstract}
A B S T R A C T
The response of a coastal region to sea-level rise depends on the local physical features, which should therefore be evaluated locally to provide an accurate vulnerability assessment. In this study, we conducted comprehensive analyses of the potential impacts of sea-level rise on the Pearl River Estuary (PRE), China with the aid of a fully calibrated three-dimensional hydrodynamic model. We found that in general, the salinity, stratification and tidal range will increase as the sea-level rises. Clear spatial variations were apparent in the response of these parameters, with different patterns occurring in different seasons. The strongest salinity increase was mostly at the front of the PRE, where freshwater and saltwater meets. In Lingding Bay (LDB), the rate of increase in stratification in response to the sea-level rise was found to be higher during high-flow conditions than that during lowflow conditions. The increases of tidal range and tidal current were amplified in the upstream direction, with the largest increase occurring in the upper tributaries. The change of vertical transport process in the PRE is not prominent and only in the upper LDB the vertical transport time increased for approximately two days. The upstream transport process was strengthened during the typical wet season and weakened during the typical dry season. The downstream transport slowed in both wet and dry seasons as the sea level rose. For a sea-level rise of $1 \mathrm{~m}$, the dry season residence time increased by 8.5 days, while the wet season residence time showed only minor changes. It was also found that the fluvial input remained in the PRE for a longer time after the sea level rose, which would increase the retention time of dissolved substances and thus effect biogeochemical processes.
\end{abstract}

\section{Introduction}

The threat of negative effects of sea-level rise on the environment has become a focus for both government and industry. Observational records and climate projections provide abundant evidence that freshwater resources are vulnerable and may be strongly affected by sea-level rise, with wide-ranging consequences for human societies and coastal ecosystems (IPCC, 2013). The direct effects of sea-level rise on estuaries not only include increased salinity and tidal currents (e.g., Hilton et al., 2008; Zhong et al., 2008; Najjar et al., 2010; Bhuiyan and Dutta, 2012), but also include alterations of physically controlled parameters such as residence time, vertical exchange, and along-channel transport timescales (Hong and Shen, 2012).

Such changes can affect water quality as well as biogeochemical processes, by altering the water-exchange processes within the system. For instance, algal blooms depend not only on nutrient loads and external physical forcings such as temperature and solar radiation but also on the residence time relative to the net growth rate (Garcon et al., 1986; Lehrter, 2008). For example, Valentim et al. (2013a) determined that sea-level rise could lead to changes in hydrodynamic parameters, which would induce significant modifications in nutrient and sediment distribution patterns around salt marshes. In a more recent study, Du et al. (2018) showed that the change of tidal range in an estuary due to sea-level rise is spatially heterogeneous and highly dependent on the length, the shape of the crosssection, and the degree of channel convergence in the estuary.

Owing to their unique topographies and hydrodynamic conditions, different estuaries show different response patterns to sea-level rise. Accordingly, the response of each coastal region to sea-level rise should be evaluated with reference to the local geological, morphological, and atmospheric conditions to optimize vulnerability assessments and local waterquality management under the background of climate change.

There is consensus in the literature that sea-level rise could cause

\footnotetext{
* Corresponding author at: School of Civil and Transportation Engineering, South China University of Technology, Wushan RD., Tianhe District, Guangzhou 510641, China.

E-mail address: bohong@scut.edu.cn (B. Hong).
} 
saline water migrate upstream to points where freshwater existed previously. Chen et al. (2015) found that the salinity profile would move $1.2 \mathrm{~km}$ further upstream if the sea-level rose by $1.05 \mathrm{~m}$ in the Tamsui River estuarine system, Taiwan. A sea-level rise of $0.55 \mathrm{~m}$ would lead to a $2 \mathrm{~km}$ upstream movement of the brackish water zone in the Weser Estuary, Germany (Grabemann et al., 2001). In the James River Estuary (an estuary in lower Chesapeake Bay, USA), saltwater would intrude about $10 \mathrm{~km}$ further upstream if the sea level rose by $1.0 \mathrm{~m}$ (Rice et al., 2012). In the Gorai River network (Bangladesh), it was found that a sealevel rise of $0.59 \mathrm{~m}$ could increase salinity by $0.9 \mathrm{psu}, 80 \mathrm{~km}$ upstream of the river mouth (Bhuiyan and Dutta, 2012).

Xiao et al. (2014) studied the effects of sea-level rise on salinity intrusion in St. Mark River Estuary (Florida, USA) and found that salinity would increase by $5.6 \mathrm{psu}$ in mid-estuary surface water and by $3.8 \mathrm{psu}$ in mid-estuary bottom water in response to a sea-level rise of $0.85 \mathrm{~m}$. Hong and Shen (2012) revealed that a rising sea-level would increase the extent of saltwater intrusion into tributaries of Chesapeake Bay, and would generate greater vertical stratification in the Bay. A study of the Changjiang (Yangtze) River Estuary indicated that a sea-level rise would cause nonlinear upstream isohaline shifts, and the shift of the 0.45 psu isohaline would be much greater than those of the 1,2 , and 5 psu isohalines with the same magnitude of sea-level rise (Chen et al., 2016).

Estuarine circulation may also be effected by sea-level rise. Zhong et al. (2008) determined that sea-level rise will change the resonance characteristics of Chesapeake Bay and suggested that the tidal range will increase by $15-20 \%$ in response to a sea-level rise of $1.0 \mathrm{~m}$. Increases in the amplitude and velocities of tidal waves due to sea-level rise have been reported in several other estuaries, e.g., Hooghly Estuary (Sinha et al., 1997), Meghna Estuary (Bangladesh) (Ali, 1995), and Changjiang River (Qiu and Zhu, 2015).

The response of residual current to sea-level rise has also been documented. Studies of Chesapeake Bay showed that the exchange flow would be strengthened but the downstream transport of freshwater would be slowed as the sea level rose (Hong and Shen, 2012). A study has also found that a rising sea level in San Francisco Bay would strengthen the longitudinal salinity gradient, which would indicate a strengthening of the gravitational circulation and an increased extent of salinity intrusion (Chua and $\mathrm{Xu}, 2014$ ). In contrast, Valentim et al. (2013b) found that a sea-level rise would induce a significant decrease in residual circulation in Tagus Estuary (Portugal); residual circulation increased slightly in some areas of the estuary mouth but decreased almost $30 \%$ in typical discharges and $10 \%$ in maximum discharges.

The Pearl River Estuary (PRE) is a bell-shaped estuary located in the northern South China Sea (SCS) (Fig. 1a). The Pearl River is the second largest river in China and has a complex river network. It has a drainage area of about $4.5 \times 10^{5} \mathrm{~km}^{2}$ and discharges freshwater into the northern SCS at eight outlets: Humen, Jiaomen, Hongqili, Hengmen, Modaomen, Jitimen, Hutiaomen, and Yamen. The total river discharge reaches a maximum in summer $\left(\sim 2.1 \times 10^{4} \mathrm{~m}^{3} / \mathrm{s}\right)$ and a minimum in winter $\left(\sim 3.4 \times 10^{3} \mathrm{~m}^{3} / \mathrm{s}\right)$ (Zhao, 1990).

Lingding Bay (LDB), with an area of almost $2000 \mathrm{~km}^{2}$, is the largest subestuary in the PRE (Wang et al., 2017), with the width at the LDB mouth being approximately $35 \mathrm{~km}$. The major axis of the LDB (the along-channel transect in Fig. 1b) is about $70 \mathrm{~km}$ from the mouth to the Humen outlet. Further northward along this transect is the Humen waterway. Bathymetric measurements have revealed that the LDB has a depth $<5 \mathrm{~m}$, except for the channels, which are 5-20 m deep. The hydrodynamics in the LDB and adjacent coastal area have been investigated in several previous studies (e.g., Ji et al., 2011; Zhen et al., 2014; Lai et al., 2015; Lai et al., 2018; Gong et al., 2018; Lin et al., 2019). These studies focus on the estuarine hydrodynamic circulation in response to wind, river discharge, tide, and waves, from the viewpoint of dynamic mechanisms.

However, limited historical data has prevented a clear assessment of the possible effect of sea-level rise on the PRE. Yuan et al. (2015) found that sealevel rise enhanced the saltwater intrusion and the landward residual current in the Hongwan and Modaomen waterways. The 0.45 isohaline (which is the salinity standard for drinking water) moved seaward in the Jiaomen and Hongqili outlets, whereas it moved landward in the Modaomen and Hutiaomen outlets. Guan et al. (2017) found that the Modaomen waterway was very sensitive to sea-level rise. The maximum salt intrusion distance shifted upstream by $1.9 \mathrm{~km}$ in response to a sea-level rise of $1 \mathrm{~cm}$.

Previous studies focused only on the problem of saltwater intrusion. The response of transport processes in the PRE to a sea-level rise has not been investigated. Under the background of accelerated global sea-level rise, investigating the responses of transport and other relevant processes in the PRE to the future sea-level rise scenarios is crucial for understanding the possible concomitant changes in the biogeochemical processes that are coupled with these physical processes.

Sea-level rise projections by the Intergovernmental Panel on Climate Change (IPCC) Fourth Assessment Report (AR4) range from 0.18 to $0.81 \mathrm{~m}$ by 2100 , with respect to the baseline year of 1990 . Church and White (2006) suggested that the global mean sea-level will continue rising during the 21st century at an increasing rate. Recent altimeter observations indicate that the rate of global sea-level rise doubled from $1.7 \mathrm{~mm} /$ year throughout most of the twentieth century to $3.4 \mathrm{~mm}$ /year since 1993 (tide gauges + satellite data) (Nicholls and Cazenave, 2010).

Tidal gauge data analysis has shown that the rate of sea-level rise in the Hong Kong coastal area (close to the PRE mouth) was $2.8 \mathrm{~mm} / \mathrm{y}$ in recent decades, and this rate is increasing (Hong et al., submitted manuscript). According to the projections of sea-level rise (IPCC, 2013), the likely global mean sea-level rise ranges from 0.53 to $0.98 \mathrm{~m}$ by 2100. Based on this information, we assessed three future sea-level rise scenarios: $0.3 \mathrm{~m}, 0.6 \mathrm{~m}$, and $1.0 \mathrm{~m}$. The extreme sea-level rise case of $1.5 \mathrm{~m}$, as suggested by a number of publications (e.g., Najjar et al., 2010), were also assessed. To isolate the effects of sea-level rise, we excluded the potential climate change-driven alterations of coastline, precipitation, wind, and other factors.

The main objective of this study was to quantify the response of the PRE hydrodynamic conditions to the sea-level rise scenarios. The possible effect of sea-level rise on biogeochemical processes coupled with physical processes was also examined. A three-dimensional numerical model based on the trend of these changes with respect to the magnitude of sea-level rise was developed to facilitate a coastal zone vulnerability assessment and optimal local water quality management. The remainder of this paper is organized as follows. Section 2 describes the methods, Section 3 details the validation of the numerical model, the results are presented in Section 4, and a discussion and conclusions are provided in Sections 5 and 6, respectively.

\section{Methods}

\subsection{Numerical model}

A three-dimensional hydrodynamic model EFDC (the Environmental Fluid Dynamics Code) was used to reproduce the hydrodynamic circulation in the PRE. This model was developed by the Virginia Institute of Marine Science, and a detailed description of it can be found in Hamrick and Wu (1997). The model uses a boundary-fitted curvilinear grid in the horizontal and sigma grids in the vertical. It has been successfully applied to model the hydrodynamics in many coastal area such as Chesapeake Bay (Hong and Shen, 2012), estuaries in Virginia, USA (Shen and Haas, 2004; Gong et al., 2009; Hong et al., 2018), the Perdido Bay Estuary, Florida/Alabama, USA (Xia et al., 2011), and the PRE (Gong et al., 2014; Hong et al., 2016; Wei et al., 2016).

The model grids and computation domain of this study are shown in Fig. 1a. The horizontal resolution ranged from approximately $40 \mathrm{~m}$ inside the PRE to approximately $1000 \mathrm{~m}$ in the shelf area. The open boundary was extended far from the PRE mouth to exclude the effect of open boundary conditions. The vertical sigma-coordinate had 20 layers that were logarithmically distributed, with higher resolution near the surface and bottom. As the Pearl River Delta (PRD) is densely populated and surrounded by several large cities, the Chinese government has conducted a great deal of shoreline-protection work in the area since the 1980s. Accompanying the rapidly accelerated industrialization and 

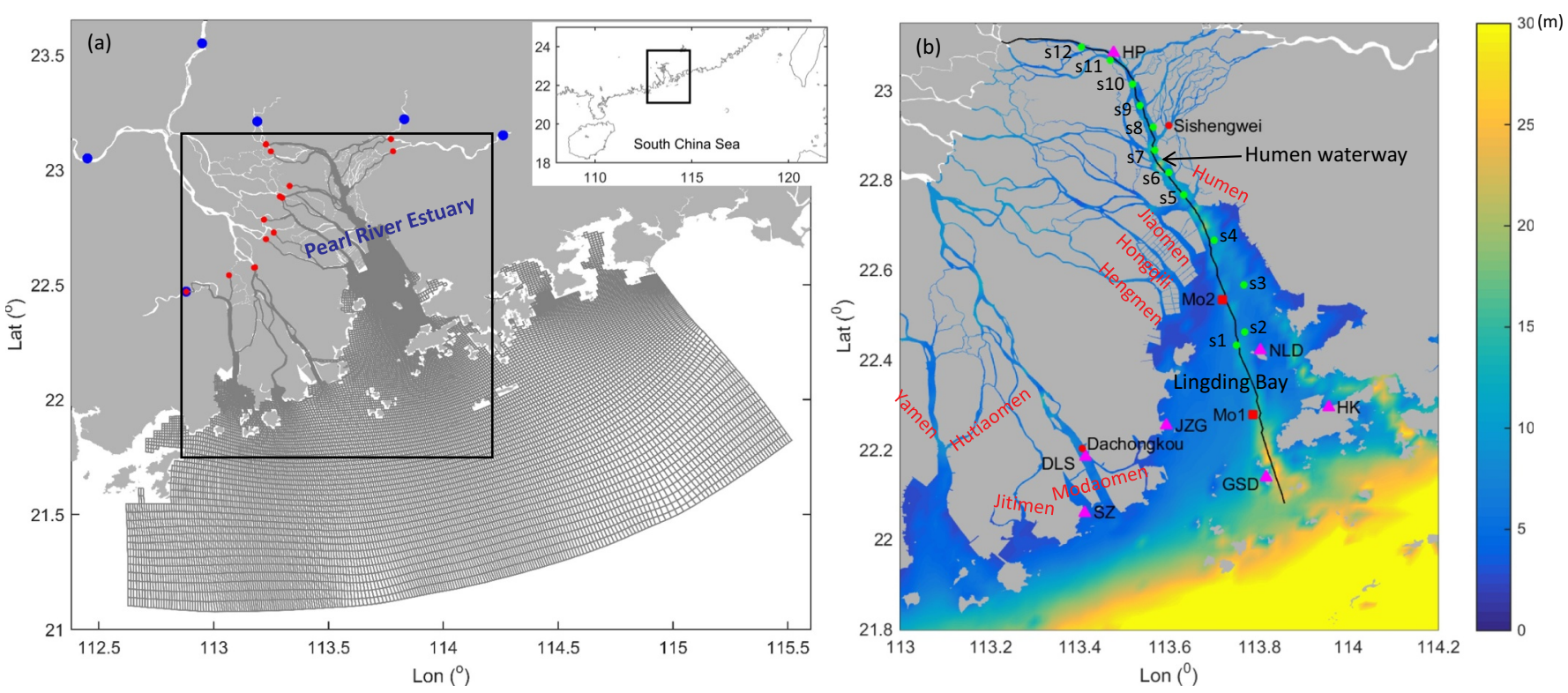

Fig. 1. (a) A map of Pearl River Estuary and numerical simulation model grids. The red dots mark the location where upstream river flow entered the model domain and the blue dots represent the stations where the in situ daily river discharge were obtained in the major tributaries of the Pearl River; (b) The bathymetry (m) of Pearl River Estuary and locations of observation stations for tidal water level (magenta triangles), salinity transect (green dots from upper Lingding Bay to Humen waterway, denoted s1 to s12), salinity (red dots) and Mooring observation (red squares, Mo1 and Mo2, where Mo1 measured velocity data and Mo2 measured both salinity and velocity). The along-channel transect for later analyses is denoted by the black line in the channel. The tidal water level stations are Huangpu (HP), Neilingding (NLD), Jiuzhougang (JZG), Hongkong (HK), Guishandao (GSD), Denglongsha (DLS), and Sanzao (SZ). Eight outlets in the Pearl River Delta are also marked. (For interpretation of the references to colour in this figure legend, the reader is referred to the web version of this article.)

urbanization, extensive marine reclamation has also been conducted over the past decades in the PRD. As a result, the shorelines around the PRE are mostly hardened, with only limited wetland areas. Therefore, the parameters of wetting and drying would have had only minor effects on our results and were thus excluded from the model.

The model was initialized by interpolating the observed winter-time salinity and temperature profiles to the model grids. The location where upstream river flow entered the model domain is marked in Fig. 1a. These open boundaries were located in the area with crisscrossed water channels. As there was no data available to directly specify the open boundary conditions in these water channels, the daily river discharge data observed at stations in the major tributaries of the Pear River (as shown in Fig. 1a; data obtained from the Pearl River Information Center of Water Resources of PR China, http://xxfb.hydroinfo.gov.cn) and the ratio of freshwater distribution among eight outlets (PRWRC, 1991; Cheng, 2001) were used to determine the distribution of river discharge in each water channel. This method has been shown to provide the best model of the river runoff distribution to each water channel and the correct freshwater-saltwater interaction in the PRE (e.g., Lu and Gan, 2015; Wong et al., 2003; Zhou et al., 2012; Zhai et al., 2005).

The model was forced at the ocean boundary by the tidal elevation obtained from the TPXO database (Egbert and Erofeeva, 2002), which comprised nine tidal parameters (denoted P1, Q1, O1, K1, M2, S2, N2, $\mathrm{K} 2$ and M4) and the subtidal elevation derived from the Hybrid Coordinate Ocean Model (HYCOM) outputs (http://hycom.org/hycom). The temperature and salinity open boundary information was obtained from the World Ocean Database 2013 (http://www.nodc.noaa.gov/ about/oceanclimate.html) to enable accurate modeling of the annual cycle of density variations. Wind-forcing data from Hong Kong airport (http://classic.wunderground.com) were used to model surface wind. These wind data had been compared with data from other resources and had demonstrated good consistency in both speed and direction.

\subsection{Strategy of simulating sea-level rise effect}

The sea-level rise scenarios were based on the IPCC's future sea-level projections (IPCC, 2013), and were named P30, P60, P100, and P150, corresponding to the $0.3 \mathrm{~m}, 0.6 \mathrm{~m}, 1.0 \mathrm{~m}$, and $1.5 \mathrm{~m}$ rises, respectively. The effects of sea-level rise on the PRE were studied using the following the strategy. The baseline scenario was defined as the model simulation that had the present mean sea level. For the future sea-level rise scenarios, the increased magnitude of sea level was added to the mean sea level used in the baseline scenario. Pickering et al. (2017) found that with a uniform sea-level rise of $2 \mathrm{~m}$ and a fixed present-day coastline, the model predicted a tidal amplitude change in the shelf off the PRD of $<10 \mathrm{~cm}$. In this study, the model open boundary was $\geq 110 \mathrm{~km}$ away from the PRE mouth and a sea-level rise of $1.5 \mathrm{~m}$ was assessed as the extreme case. Thus, the error introduced by the open boundary condition could be assumed to have a negligible effect on the interior characteristics of the model, meaning that the interior results were reliable for investigating the effect of sea-level rise in the PRE.

Fig. 2 presents the river discharge from the Pearl River. In the PRE, June, July and August are the wet summer season and December, January, February are the dry winter season. A comparison of the river discharge in 2007 with the long-term mean (2004-2014) data showed that the monthly mean dry season river-discharge in 2007 was very close to the long-term mean value, while the monthly mean wet season river-discharge in 2007 was lower than the long-term mean data. The model was run from 2006 to 2007 and we only analyzed the results for 2007 to exclude the influence of model spin-up.

\section{Model validation}

To evaluate the model performance in the PRE, the results from the baseline scenario were compared against all the available observed data from 2007.

\subsection{Validation of water elevation}

We define Skill $=1-\left(\sum\left(X_{\text {model }}-X_{o b s}\right)^{2} / \sum\left(\left(X_{\text {model }}-\overline{X_{o b s}}\right)+\left(X_{o b s}-\overline{X_{o b s}}\right)\right)^{2}\right)$, where $X$ is the variable being compared with a time mean $\bar{X}$. Perfect agreement between model results and observations yields a skill value of one and complete disagreement yields a skill value of zero.

The statistics of water elevation comparison are shown in Table 1. 


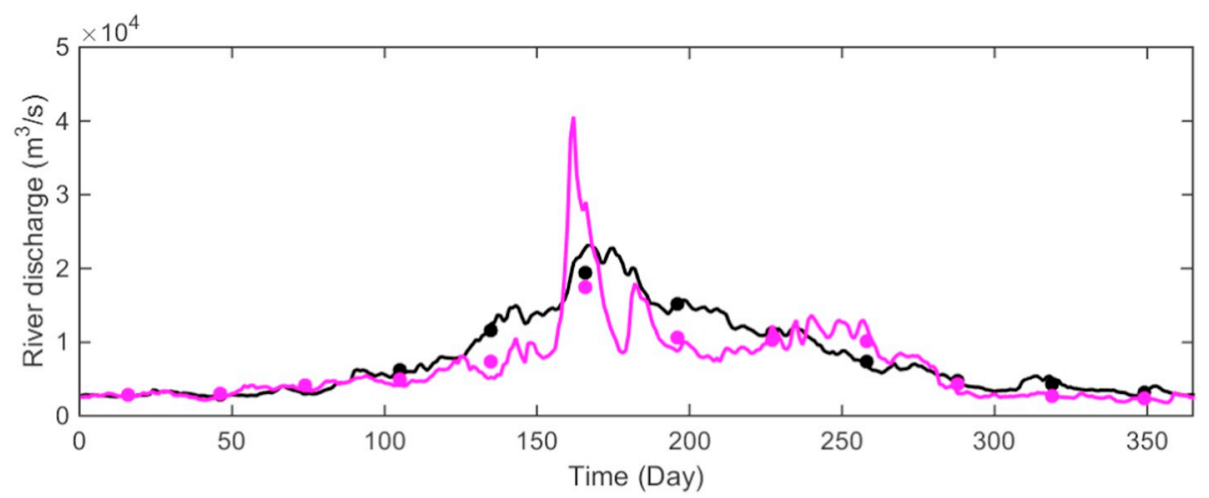

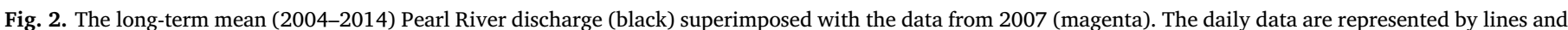

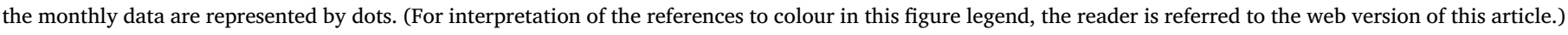

From upstream to downstream, the available stations were Huangpu (HP), Neilingding (NLD), Mooring 1 (Mo1), Hong Kong (HK), Jiuzhougang (JZG), Denglongsha (DLS), Guishandao (GSD), and Sanzao (SZ), and their locations are marked in Fig. 1b. Both the tidal and the non-tidal elevation were thoroughly compared. At stations NLD, JZG and GSD, only the tidal elevation observations were available. A better value for skill $(>0.98)$ was obtained in the tidal simulation. The skill for the non-tidal elevation at different stations ranged from 0.82 to 0.92 , which indicated that the model results were able to capture the variations of observed non-tidal elevations.

The water elevation comparison at stations HP and Mo1, which represented the upper reach and lower portion of the PRE, respectively, is presented in Fig. 3. Model results matched the observations very well. Comparisons at other stations had similar features (figures not shown). All these data indicate that the model performed consistently well in simulating both the tidal and the non-tidal elevations from upstream to the lower PRE.

\subsection{Validation of salinity}

The salinity time series data were from station Mooring 2 (Mo2; see Fig. 1b for its location). The surface, mid-depth and near bottom salinity data were measured for $50 \mathrm{~h}$, commencing at 12:00 pm on December 26, 2007. In Fig. 4a-c, the modeled salinity data are compared with the observational data. The surface layer salinity varied more due to the direct impact of wind forcing. The mid-depth and bottom layer salinity exhibited the pattern of direct influence of flood and ebb tide. The correlation coefficients between data for modeled and observed salinity from the surface to the bottom were $0.86,0.93$ and 0.95 , respectively (with a 95\% confidence level). The model performed well at reproducing the salinity structure in the PRE.

\section{Table 1}

Statistics of the model-data comparison in water elevation (m). RMS means root mean square (N.A. means the non-tidal observation data were not available).

\begin{tabular}{llllll}
\hline \multirow{2}{*}{ Huangpu } & & Mean_obs (m) & Mean_mod (m) & RMS & Skill \\
\hline \multirow{4}{*}{ Neilingding } & Non-tidal & 0.1429 & 0.0599 & 0.1554 & 0.8465 \\
& Tidal & -0.0034 & -0.0034 & 0.0846 & 0.9959 \\
& Non-tidal & N.A. & N.A. & N.A. & N.A. \\
& Tidal & 0.0016 & 0.0019 & 0.1531 & 0.9807 \\
Mooring A & Non-tidal & -0.1205 & -0.0810 & 0.1236 & 0.8423 \\
& Tidal & 0.0405 & 0.0247 & 0.2035 & 0.9677 \\
Hongkong & Non-tidal & -0.0381 & -0.0577 & 0.1220 & 0.8701 \\
& Tidal & 0.0002 & 0.0001 & 0.1244 & 0.9820 \\
Jiuzhougang & Non-tidal & N.A. & N.A. & N.A. & N.A. \\
& Tidal & 0.0012 & 0.0012 & 0.0678 & 0.9957 \\
Denglongandao & Non-tidal & N.A. & N.A. & N.A. & N.A. \\
& Tidal & 0.0008 & 0.0005 & 0.0763 & 0.9947 \\
Sanzao & Non-tidal & 0.0956 & 0.0310 & 0.1013 & 0.8224 \\
& Tidal & -0.0035 & -0.0037 & 0.0583 & 0.9965 \\
& Non-tidal & -0.0450 & -0.0452 & 0.1119 & 0.9196 \\
& Tidal & -0.0004 & -0.0004 & 0.074 & 0.9944 \\
\hline
\end{tabular}

Further model-data comparisons for salinity were made at 12 stations (S1 to S12) extending from the middle LDB to HP along the Humen waterway (marked Fig. 1b). The bottom and surface salinity were observed during spring tide (December 26, 2007) and neap tide (December 31, 2007) conditions, respectively. As shown in Fig. 4d-g, the overall model-simulated data for the spatial distribution of salinity along the LDB and Humen waterway were in good agreement with the observations. Moreover, the surface and bottom salinity difference was much larger during the neap tide than that during the spring tide, and the observed stratification/destratification responses to the spring and neap tidal conditions were also well reproduced by the model result.

More salinity data were obtained at stations Sishengwei and Dachongkou (marked in Fig. 1b). At station Sishengwei, the bottom salinity was measured twice daily (at high and low tide) from January 18 to April 20, 2008. In comparison with the modeled hourly data (Fig. 4h), the modeled salinity data have good consistency with the observational data from both high tide and low tide. The spring-neap variation in salinity was also well reproduced by the model.

At station Dachongkou, the hourly observation data was obtained from February 9 to April 30, 2008. The modeled salinity was highly consistent with the observed data both in its spring-neap and seasonal variations (Fig. 4i). As the PRE river flow increases from April, the salinity of the upper estuary show rapid responses of decreasing in both the Humen waterway and the Modaomen waterway. These long-term comparisons of model-derived and observational salinity data confirmed that the model was robust in simulating the salinity variations in the PRE.

\subsection{Validation of velocity}

Velocity data were available from stations Mo1 and Mo2. At station Mo2, the surface, mid-depth and near bottom velocity data were measured at the same time as the salinity data shown in Section 3.2. The comparison of the along-channel and cross-channel velocity is presented in Fig. 5. The diurnal inequality of velocity was well reproduced in different layers (Fig. 5a-f). Both the phase and the speed of the modeled current matched the observational data. The mid-depth and near-bottom velocity displayed consistent variations. The surface velocity show more prominent variations due to surface forcing field.

At station Mo1, the near-bottom velocity (at $8.3 \mathrm{~m}$ in depth) was measured in both summer and winter of 2007 . These data facilitated the validation of velocity in both the wet (summer) and the dry (winter) seasons. As shown in Fig. $5 \mathrm{~g}-\mathrm{j}$, the modeled velocity compared favorably with the observations. The correlation coefficients (with 95\% confidence level) for the summer and winter velocity ranged from 0.86 to 0.91 . The near-bottom along-channel velocity was stronger in summer than in winter, which was consistent with the stronger gravitational circulation of the PRE in the wet season. These findings showed that the model reliably simulated both the tidal and gravitational circulation in the PRE. 

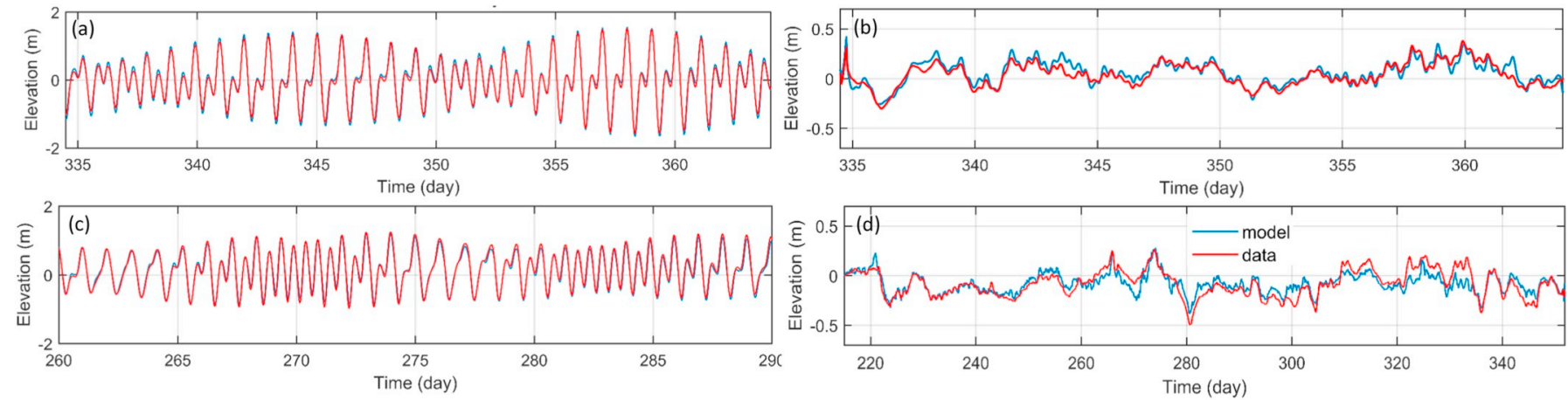

Fig. 3. The tidal and non-tidal water elevation comparisons from stations Huangpu (a, b) and Mo1 (c, d).

\section{Results}

\subsection{Pattern of salinity increase}

To quantify the spatial variations of salinity change, the salinity difference between the baseline scenario and each sea-level rise scenario were plotted for the along-channel transect of the PRE (see Fig. 1b for the location). As shown in Fig. 6, remarkable seasonal variations were found in the monthly averaged results. During the typical wet season (June; monthly mean river discharge $=1.06 \times 10^{4} \mathrm{~m}^{3} / \mathrm{s}$ ), the salinity increased in the upper portion of LDB (approximately from station Mo1 to S4) and the salinity increase in the bottom layer was much greater than that in the surface layer. For a $1.0 \mathrm{~m}$ sea-level rise, the bottom layer salinity increase was found to be $>5 \mathrm{psu}$, while at the surface, it was only about 1 psu. Although the maximum salinity increase during the typical dry season (January; monthly mean river discharge $=2.88 \times 10^{3} \mathrm{~m}^{3} / \mathrm{s}$ ) was smaller than that during the wet season, this salinity increase spanned a much larger area, extending from the upper LDB across most of the Humen waterway,
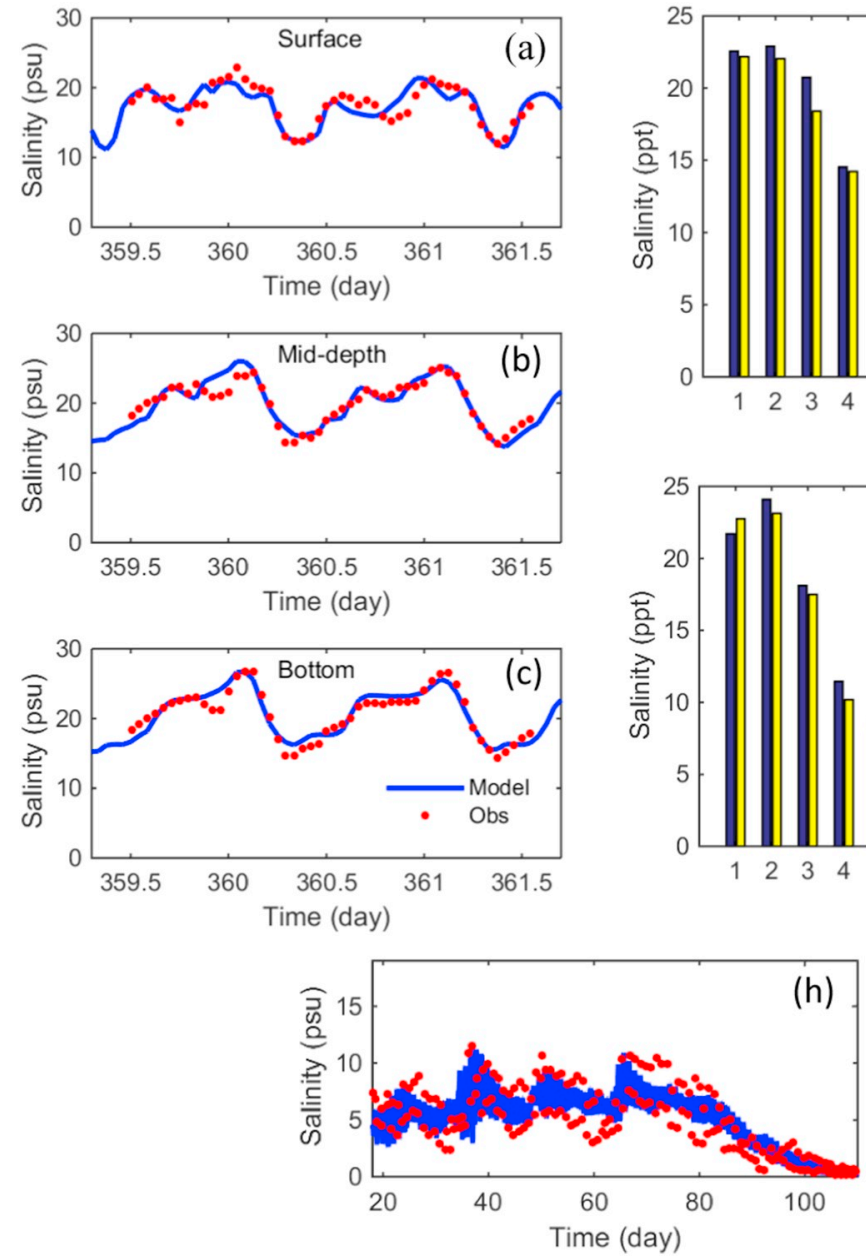
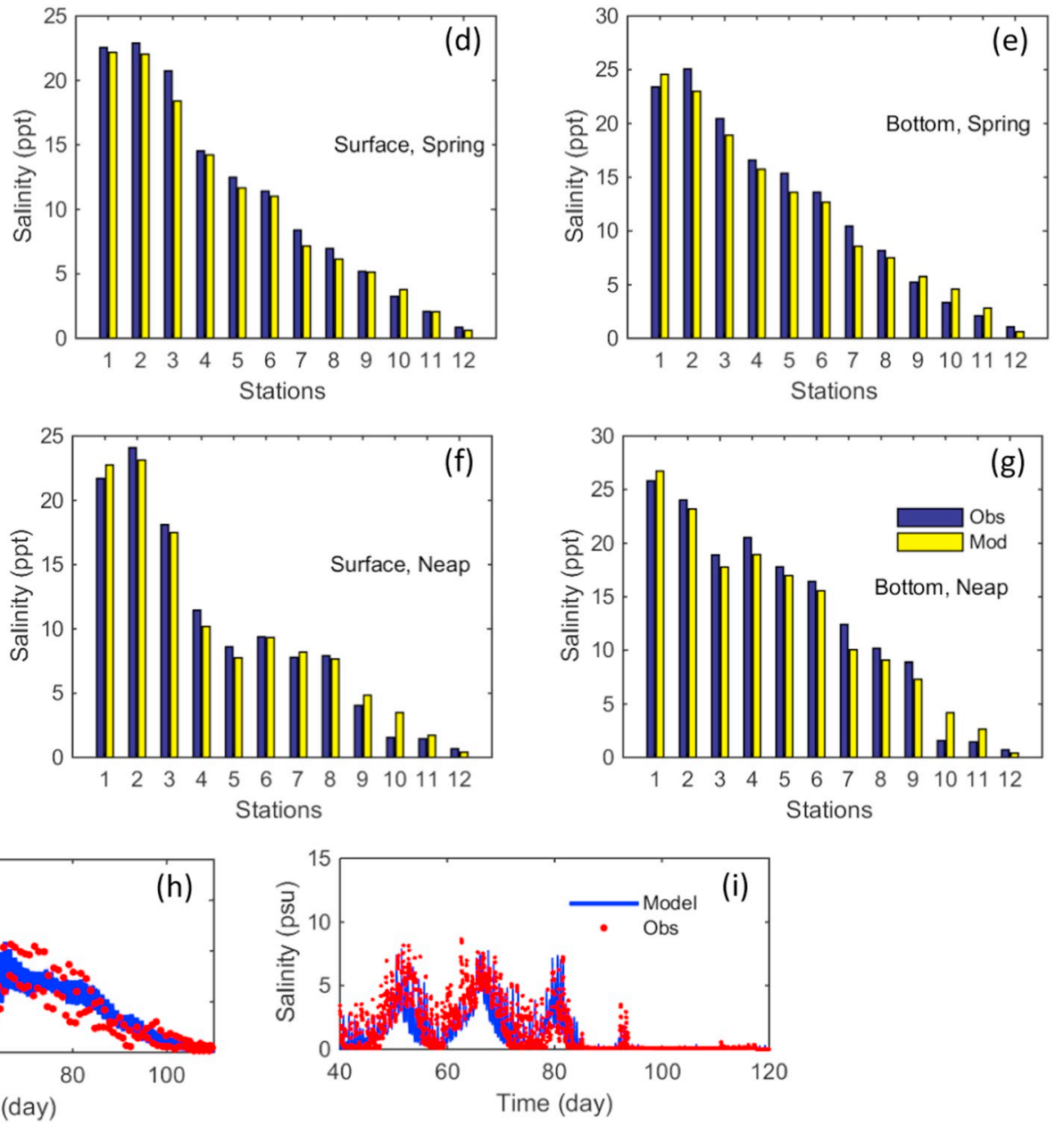

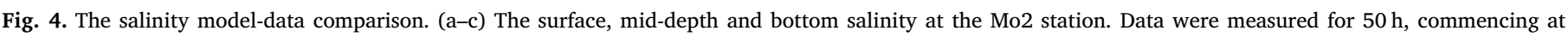

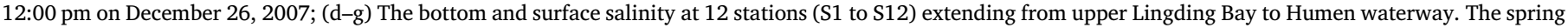

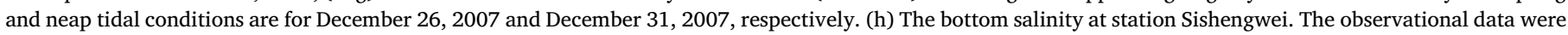

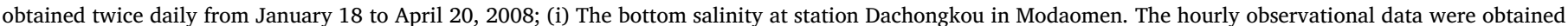
from February 9 to April 30, 2008. 

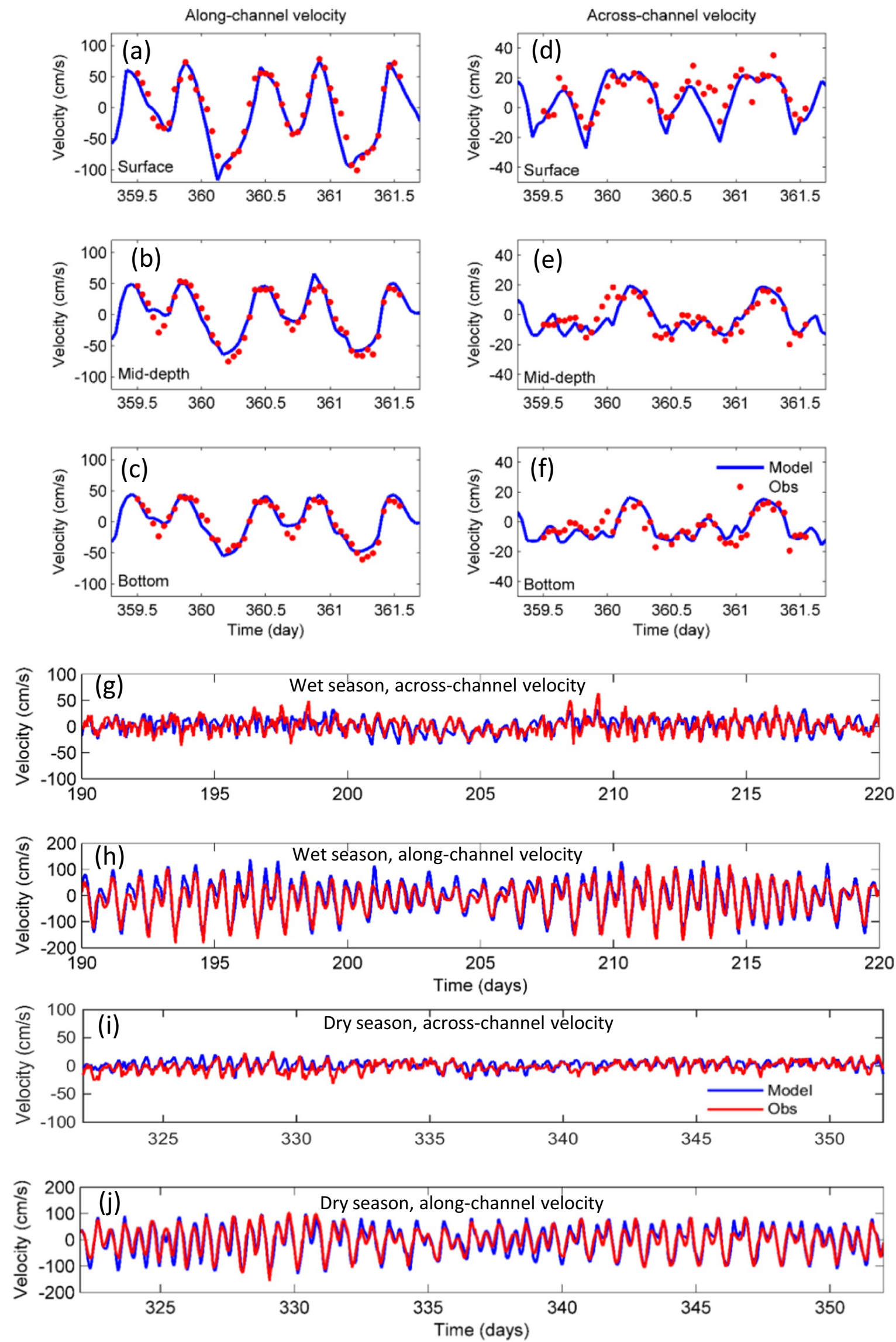

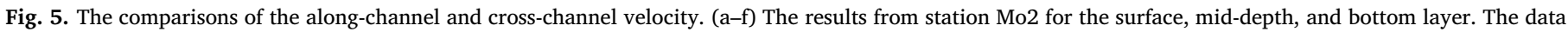

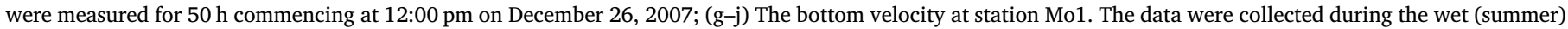
and dry (winter) season of 2007. 

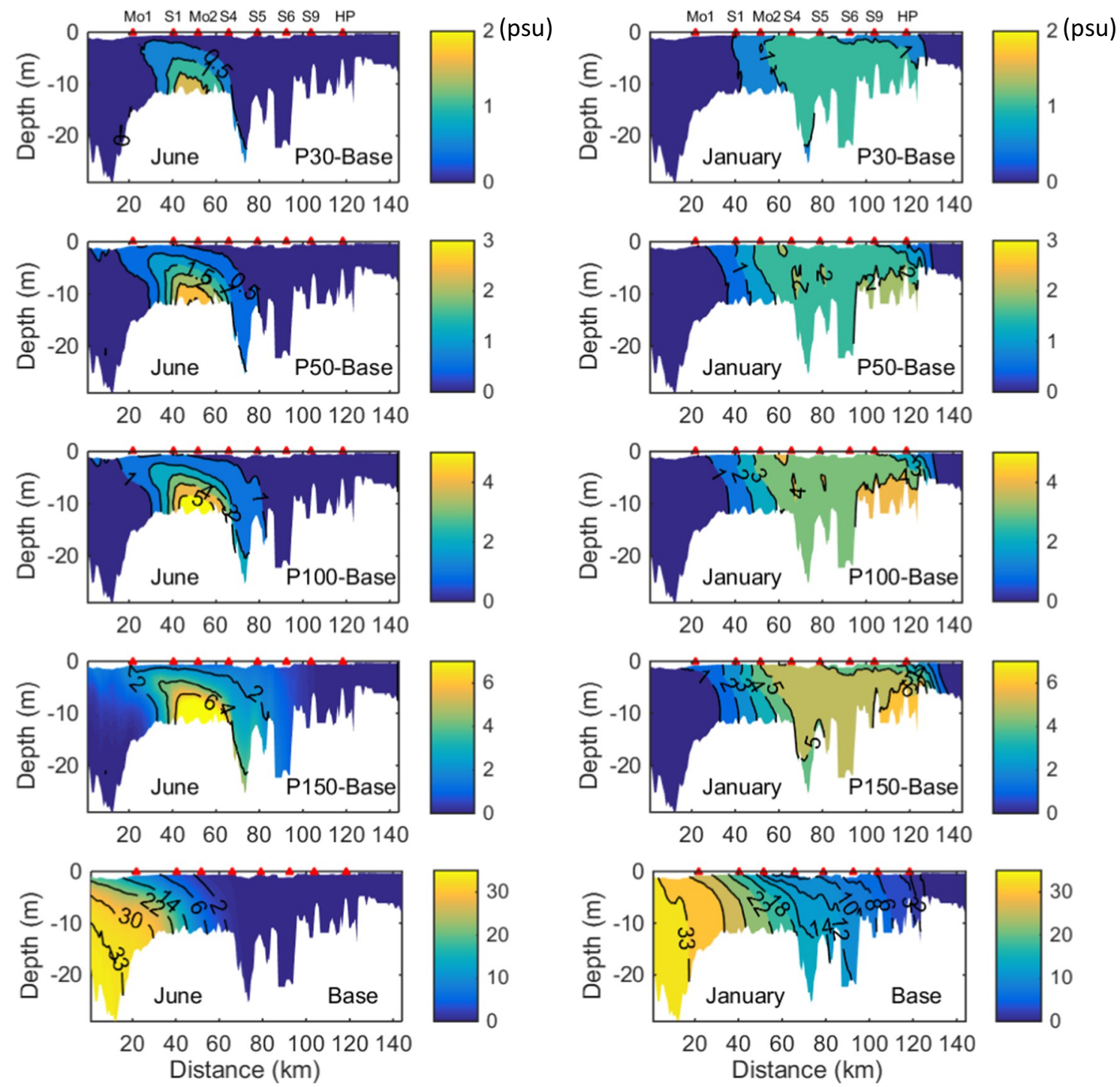

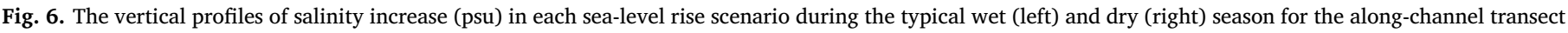

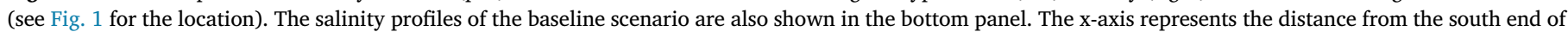
the along-channel section. For reference, the stations that are near the transect are marked.

with only minor vertical salinity variations in the water column. Compared with the salinity distribution in the baseline scenario, the largest salinity increases as a result of sea-level rise were located in the front area of the $\mathrm{LDB}$, where freshwater and saltwater meet.

The Bay-wide volume mean salinity was used to identify the trend of salinity change with respect to the sea-level rise. The salinity of the water body in LDB and upper tributaries were calculated separately owing to their different hydrodynamic conditions. As shown in Fig. 7a and b, the volume mean salinity increase during the dry season was higher than that during the wet season. This could be explained by the data in Fig. 6 which shows that sea-level rise during the dry season resulted in a salinity increase across a much larger area and thus led to a higher volume mean salinity increase.

The trend of mean salinity change with respect to the sea-level rise is presented in Fig. 7c. The mean salinity increase rate during the dry season was larger than that during the wet season. The LDB and upper tributaries had similar trends during the dry season. However, the situation was quite different during the wet season, during which there were only very minor changes in the mean salinity in the upper tributaries. This showed that the sea-level rise had a very minor impact on the upstream tributaries during the wet season.

With a sea-level rise of $1.0 \mathrm{~m}$, the Bay-wide increase in mean salinity in LDB would be 3 and 2 psu during the dry and wet seasons, respectively. Such a change could cause the upstream shift of aquatic habitats.

\subsection{Variations of vertical stratification}

Vertical stratification is a very important factor that is frequently used to determine the stability of a water column. Strong vertical stratification in estuaries usually results from the intense halocline, which functions as a barrier for dissolved oxygen (DO) vertical exchange between the bottom layer and the oxygenated surface water. Hypoxia (DO concentration < $2 \mathrm{mg} / \mathrm{L}$ ) in bottom waters has been widely reported to coincide with the strong stratification in coastal waters, e.g., PRE (Cui et al., 2018), Chesapeake Bay (Scully, 2010; Murphy et al., 2011; Hong and Shen, 2012Hong and Shen, 2013), Long Island Sound, USA (Wilson et al., 2008).

Being a bell-shaped estuary, the PRE does not have the relatively stable stratification of Chesapeake Bay. As a result, sporadic hypoxia has been observed in the PRE in summertime (Cui et al., 2018). The response of stratification to sea-level rise was important to evaluate to assess the vulnerability of the PRE to climate change.

We used the Brunt Väisälä Frequency $\left(N^{2}\right)$ as an index to measure the stratification strength at every depth $z_{i}$, where $N^{2}\left(z_{i}\right)=-(g /$ 

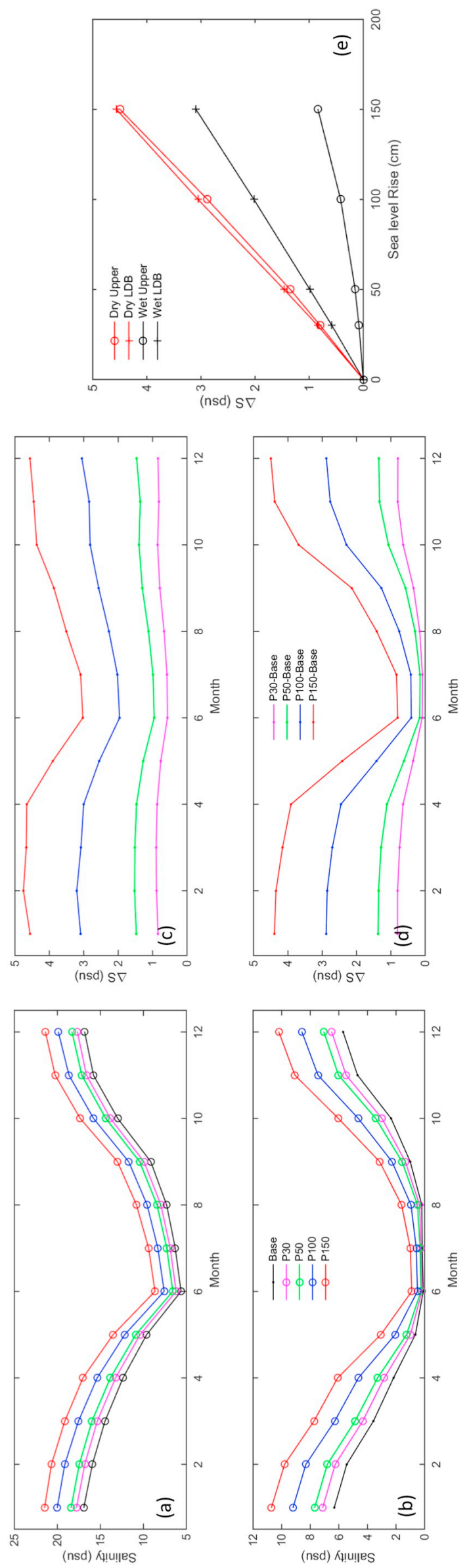

$\left.\rho_{i}\right) \cdot(\partial \rho / \partial z), g$ is the gravitational constant, $\rho_{i}$ is the water density (in $\mathrm{kg} /$ $\mathrm{m}^{3}$ ) at depth $z_{i}$ and $\partial \rho / \partial z$ is the density gradient at depth $z_{i}$. The maximum $N^{2}$ in a given water column is defined as the pycnocline strength and was used in our study to represent the stratification strength. Fig. 8 shows the results calculated for each water column as determined by the model grids in Fig. 1a and then averaged in LDB and the upper tributaries. For clarity, only the monthly results are shown.

The stratification in both LDB and the upper tributaries was strengthened as the sea level rose. However, the increase of stratification intensity was not consistent across the entire PRE. The LDB had a stronger increase, and this was greater during the wet season than during the dry season. The change of stratification intensity in the upper tributaries showed clear seasonal variations, with the increase of stratification during the transition period (spring and autumn for the PRE) being much larger than that during the typical wet and dry seasons.

The trend of stratification change with respect to the sea-level rise is shown in Fig. 8e. The results for June, September and December were plotted to represent the conditions during the typical wet season, the transition period, and the typical dry season, respectively. It can be seen that stratification responded differently to sea-level rise under different hydrodynamic conditions. In the upper tributaries, the rate of stratification increase was higher during the transition period, which indicated that the upper tributaries were more susceptible to the sea-level rise in that period. In the LDB, the rate of stratification increase was higher for estuary with high flow. Given a sea-level rise of $1.0 \mathrm{~m}$, the summertime stratification would increase by $20 \%$ in the LDB, which may result in more frequent hypoxic events in the PRE.

\subsection{Changes of tidal range}

Tides in the PRE are semi-diurnal with prominent diurnal inequality (Dong et al., 2006). The tidal range in the PRE is between 1.0 and $1.7 \mathrm{~m}$ (Ye and Preiffer, 1990), and the M2 semidiurnal tide is the dominant tidal constituent, followed by $\mathrm{K} 1, \mathrm{O} 1$, and $\mathrm{S} 2$. When propagating upstream from the offshore side of the PRE, the M2 amplitude increases by approximately $80 \%$, which is much larger than the increase of the amplitudes of K1, O1, and S2 (Mao et al., 2004).

Here, we compared the M2 tidal amplitude between the baseline scenario and the case with $1.0 \mathrm{~m}$ sea-level rise. The results of this are presented in Fig. 9a, wherein it can be seen that the M2 tidal amplitude increased over the entire PRE. This increase was amplified toward the upstream regions and the greatest increase occurred in the upper tributaries. These results indicated that the effect of sea-level rise on the tidal elevation could be amplified as the tidal wave propagated from the lower open estuary to the less open upstream regions.

Stations HP and DLS were selected to show the changes of tidal range in the upstream and lower part of the PRE, respectively (Fig. 9b and c). The increase of tidal range in the upstream region was very prominent. For a sea-level rise of $1.0 \mathrm{~m}$, the tidal range could increase by $23 \%$ at the station HP. Similar to the results in studies of Chesapeake Bay (Hong and Shen, 2012) and Hooghly Estuary, Bay of Bengal (Sinha et al., 1997), these data also shows that both low and high tides arrive early throughout the PRE after sea-level rising. The amplification of tidal range in the upstream region is due to both the estuarine length and channel converging (Du et al., 2018), and such a feature can also be observed from the tidal current (Fig. 9d and e). The results from station Mo2 clearly showed that tidal current can be strengthened due to sea-level rise. The maximum flood and ebb currents arrived earlier in the sea-level rise scenarios. The increase of tidal current in the surface layer was more larger than that in the bottom layer, with the former modeled to increase about $16 \%$ at the Mo2 for the $1.0 \mathrm{~m}$ sea-level rise scenario.

\section{Discussion}

\subsection{Impact on the vertical transport processes}

Results shown in Section 4 indicated that sea-level rise would not 

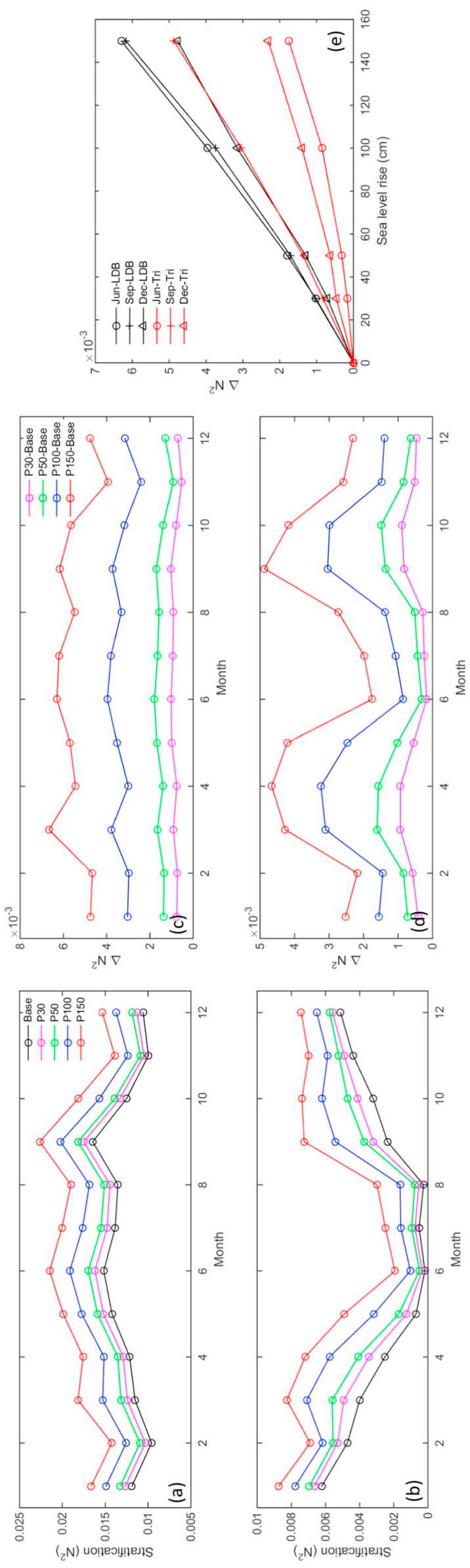

only strengthen the stratification but also increase the tidal amplitude in the PRE. It has been a consensus among researchers that vertical transport would be weakened if the stratification in an estuarine water column is strengthened. However, an increase of tidal amplitude would intensify the vertical mixing and thereby strengthen the vertical transport. Thus, it needed to be examined whether vertical transport in the PRE would be weakened if the sea levels rose.

Regular hydrodynamic variables are difficult to use to evaluate the vertical transport process. Thus, vertical transport time (VET) was used to evaluate the changes in vertical transport. Following the strategy of Hong et al. (2016), the VET was calculated as a mean water age, which is governed by the following Eqs. (1) and (2):

$\frac{\partial c(t, \vec{x})}{\partial t}+\nabla \cdot(V c(t, \vec{x})-K \cdot \nabla c(t, \vec{x}))=0$

$\frac{\partial \alpha(t, \vec{x})}{\partial t}+\nabla \cdot(V \alpha(t, \vec{x})-K \cdot \nabla \alpha(t, \vec{x}))=c(t, \vec{x})$

where $c(t, \vec{x})$ is the tracer concentration, $\alpha(t, \vec{x})$ is the age concentration, $V$ is the velocity vector, $K$ is the diffusivity tensor, $\nabla=\mathrm{i} \frac{\partial}{\partial x}+j \frac{\partial}{\partial y}+k \frac{\partial}{\partial k}, t$ is time, and $\vec{x}$ is the spatial coordinate. In addition, there was no sink of tracer within the study area. According to Deleersnijder et al. (2001), the transport time $\tau(t, \vec{x})=\alpha(t, \vec{x}) / c(t, \vec{x})$. VET represented the elapsed time since the water was last in contact with the water surface. Thus, the water age at any location represented the vertical transport time required for the water parcel to be transported from the water surface to that location, regardless of its pathway.

In a typical dry season, the estuary was well mixed and it took only approximately two days for the tracer to be transported from the water surface to the bottom layer (figure not shown). As the hypoxic events mainly occurred in the wet season in areas of stronger stratification, only the monthly mean results in June are shown in Fig. 10 (the results for July showed a similar pattern). These data show that in the LDB the VET increased from two days in the upper estuary to $>18$ days in the area around the estuary mouth. In the $1.0-\mathrm{m}$ sea-level rise scenario, the increase of VET mainly occurred in the upper portion of LDB, and the maximum increase was approximately two days. Thus, unlike Chesapeake Bay, the VET increase in response to sea-level rise in the PRE is minor and is confined to the upper estuary. Few hypoxic events have appeared in this area in the past three decades (see Fig. 14d in Cui et al., 2018).

The location of the VET increase was coincident with the area that experienced the salinity increase (see Fig. 6). In this area, the increase of vertical stratification in the water column overwhelmed the increased effect of tidal mixing, which led to the increase of VET. According to the study of Cui et al. (2018), an intense halocline can be observed around the PRE mouth during the wet season, caused by the strong river plume. The resulting pycnocline formed a barrier layer and thus inhibited vertical exchange and lead to hypoxia in this area. Our data suggest that sealevel rise effects will not increase the VET around the PRE mouth, and thus will not increase the possibility of hypoxia around this area.

\subsection{Impact on the along-channel transport processes}

A deep-layer landward inflow exists in all estuaries, despite their tidally averaged net seaward flow caused by river discharge. The persistent bottom layer inflow and associated strong stratification traps particles, larvae, nutrients, and low-oxygen water, giving rise to both the high biological productivity and persistent water-quality problems of these environments (MacCready and Geyer, 2010). However, the terrestrial inputs from a river network transport high nutrient loads to an estuary, and such inputs have been found to correlate with hypoxia, harmful algal blooms, and similar events in estuaries (Hagy et al., 2004; Murphy et al., 2011).

The fate and pathway of these dissolved substances are controlled by along-channel transport processes. It is thus important to assess the impact of sea-level rise on the along-channel transport processes in the PRE. By using Eqs. (1) and (2), the along-channel transport time scale of dissolved substances derived from the river head or the open sea can be 

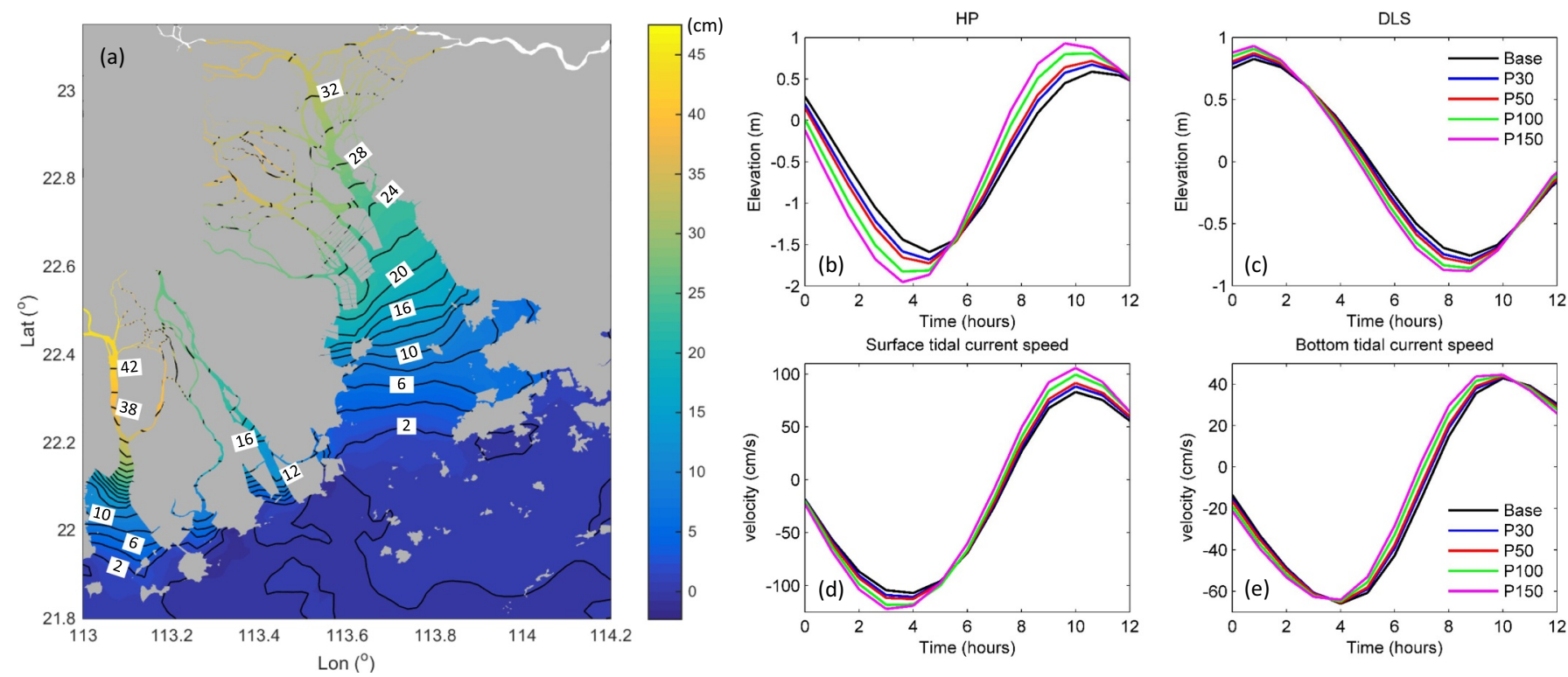

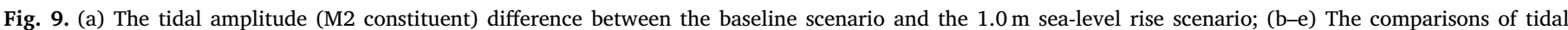

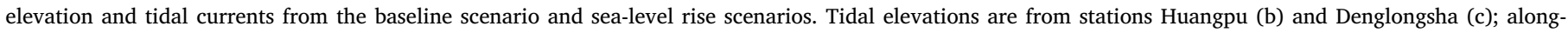
channel tidal current at station Mo2 for surface (d) and bottom (e) layer.

calculated. The downstream transport time indicates the residence time of freshwater. The upstream transport time indicates the strength of the exchange flow (MacCready and Geyer, 2010).

Fig. 11 presents the upstream transport time along the main channel of the PRE for the baseline scenario and the $1.0 \mathrm{~m}$ sea-level rise scenario. During a typical wet season, upstream transport time was reduced, which meant that the exchange flow was strengthened as the sea level rose. However, during the dry season, the upstream transport time was increased by approximately ten days, which meant that the exchange flow was weakened as the sea-level rose.

It was interesting to see the sea-level rise had opposing effects on the upstream transport in different seasons. The main reason for this was the less stratified water column during the dry season, resulting from the low river discharge and comparatively strong winter monsoon. However, in this dry winter season, the river plume extends only into the western part of the estuary and the coastal water intrudes into the
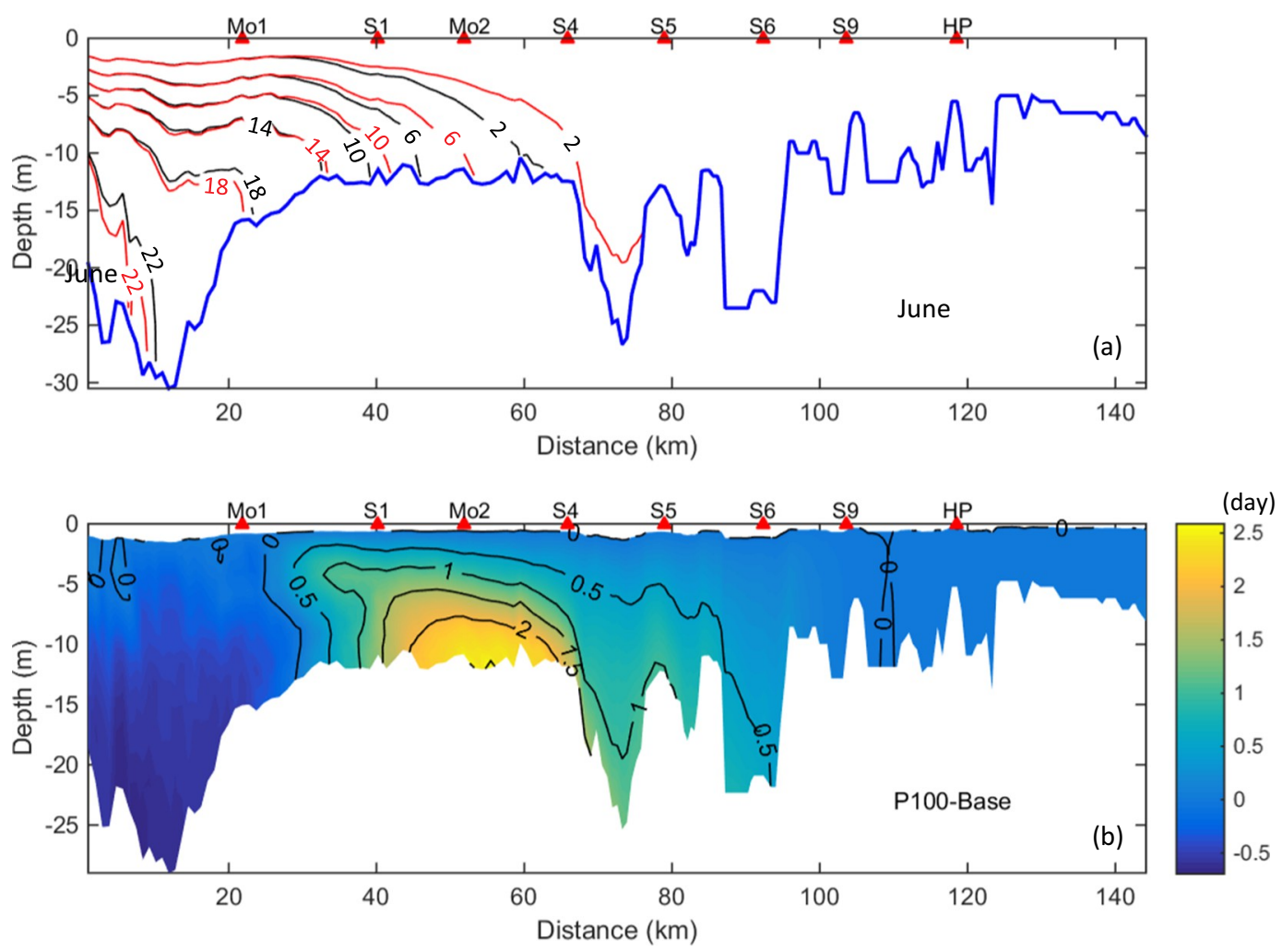

Fig. 10. (a) The along-channel transect of vertical transport time (day) during the typical wet season (June). Results from the baseline scenario and the scenario with a 1.0-m sea-level rise (P1m) are represented by the black lines and red lines, respectively; (b) The difference in vertical transport time (day) between the baseline scenario and $\mathrm{P} 1 \mathrm{~m}$ (P1m - baseline scenario). The location of the transect is shown in Fig. 1b. 

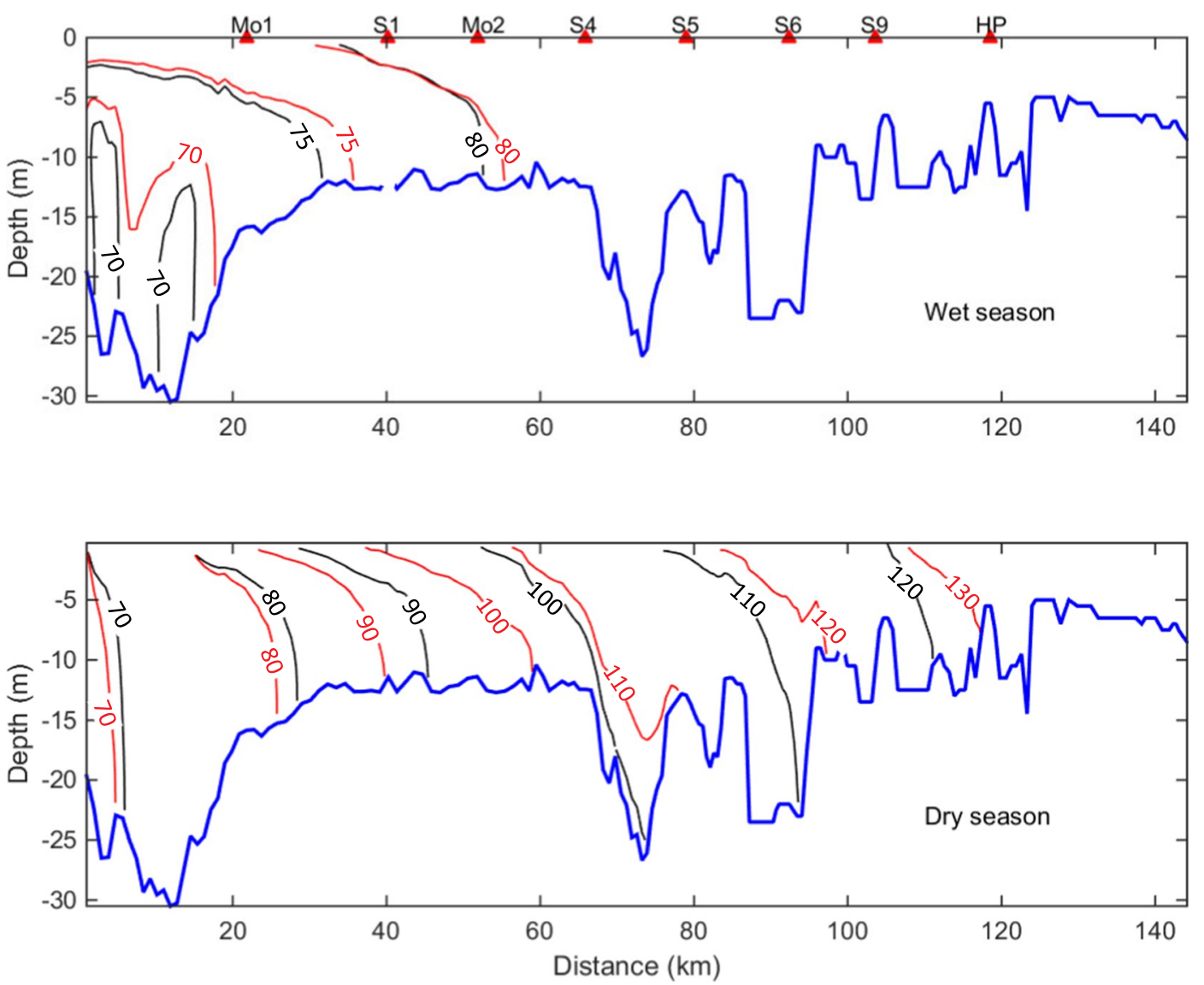

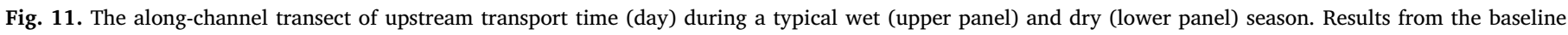

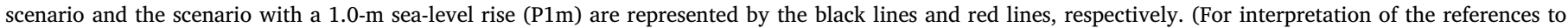
colour in this figure legend, the reader is referred to the web version of this article.)

eastern part of the estuary through channels, which results a salinity gradient in the PRE that runs from the northwest with riverine water to the southeast with more saline coastal waters (Xu et al., 1981; Ji et al., 2011, Lai et al., 2016). Therefore, the PRE circulation during the dry season is more like coastal circulation rather than the classical twolayered gravitational circulation described by MacCready and Geyer (2010). This circulation pattern is distinct from the upstream transport characteristics in Chesapeake Bay (Hong and Shen, 2012).

The data also show that it took an additional 20 days for dissolved substances to be transported from the estuary mouth to the upper LDB during the dry season in comparison with the result during wet season (black lines in Fig. 11a and b).

The downstream transport time along the main channel of the PRE is presented in Fig. 12. The transport time of tracers coming from the river head increased approximately 6 days during the wet season and approximately 10 days during the dry season in the scenario with a $1.0 \mathrm{~m}$ sea-level rise. These results indicated that the fluvial input will remain inside the PRE for a longer time after a sea-level rise, which will affect the biogeochemical processes by increasing the retention time of dissolved substances. These results are similar to those found in studies of Chesapeake Bay (Hong and Shen, 2012) and the Tamsui River (Chen et al., 2015).

As the mean residence time is usually used to evaluate the transport processes in an estuary, the mean residence time of the PRE (excluding the tributaries located on the west of the LDB) was calculated. Tracers were released simultaneously throughout the entire LDB and upper tributaries. The hydrodynamic conditions of wet season and dry season were considered, separately. The residence time corresponded to the time when the mean tracer concentration reached its e-folding value. The results (Fig. 13) suggested that, during the dry season, the residence time of the PRE increased by approximately 8.5 days in the $1 \mathrm{~m}$ sea-level rise scenario. During the wet season, the residence time increased only slightly, and this accounted for only $10 \%$ of the result in the baseline scenario. The residence time during the dry season (35 days) was longer than that during the wet season (6 days).

The regulation of different forcing factors on the residence time will be investigated in a separate manuscript. The results we have presented here show that, according to our model, sea-level rise had a greater impact on the residence time under the low-flow conditions, due to weaker vertical stratification. Strong gravitational circulation can be developed under the high river discharge, resulting in a fast renewal of water mass in the PRE.

\section{Conclusions}

The possible response of a certain coastal region to sea-level rise should be evaluated according to the local geological and morphological conditions to obtain an accurate vulnerability assessment. Previous studies on the effects of sea-level rise in the PRE focused only on the saltwater intrusion problem. Comprehensive assessments of the response of multiple physical parameters and transport processes to projected sea-level rise scenarios in the PRE are rare. In this study, a series of important results about the effects sea-level rise in the PRE were obtained with the aid of a fully calibrated 3-D numerical model.

In the PRE, the volume mean salinity increase rate with respect to the sea-level rise during the dry season was found to be higher than that during the wet season. However, the maximum bottom layer salinity increase during the wet season was higher than that during the dry season. The greatest salinity increase occurred mainly in the front area of the LDB, where freshwater and saltwater meet. The PRE is a partially mixed estuary and thus does not have the relatively stable stratification seen in other coastal waters, such as Chesapeake Bay. 

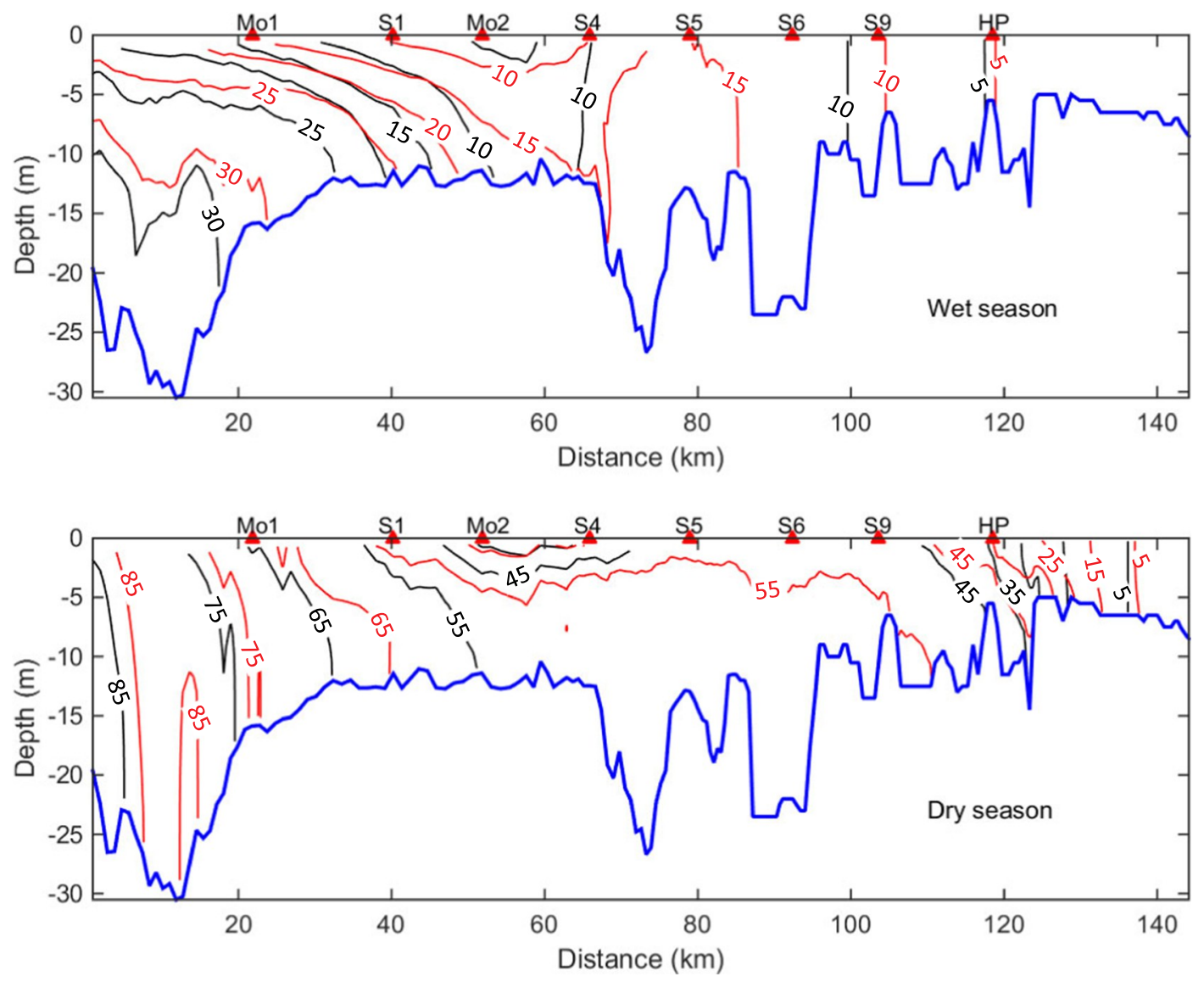

Fig. 12. Same as Fig. 11, but for the downstream transport time (day).

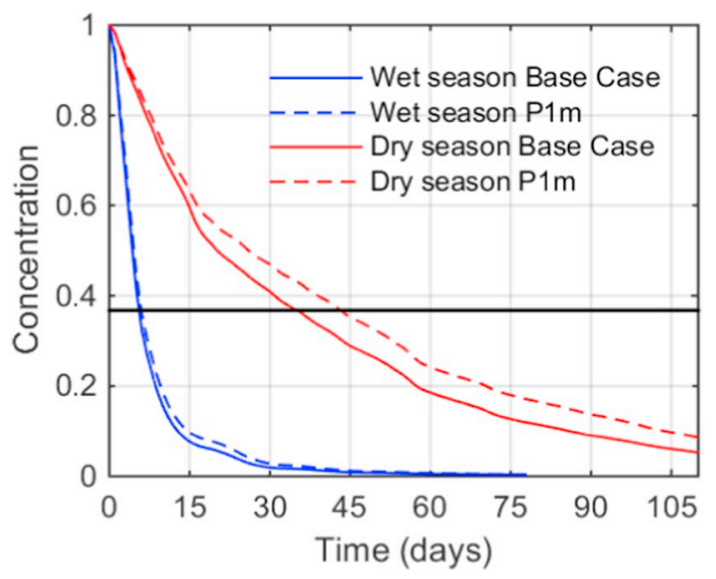

Fig. 13. The residence time for the entire Lingding Bay during the wet season (blue lines) and the dry season (red lines), respectively. The results for the baseline scenario and the scenario with a $1.0-\mathrm{m}$ sea-level rise $(\mathrm{P} 1 \mathrm{~m})$ are represented by the solid lines and dashed lines, respectively. (For interpretation of the references to colour in this figure legend, the reader is referred to the web version of this article.)

The stratification in LDB was strengthened as the sea-level rose, and its rate of increase in the high-flow conditions was higher than that in the low-flow conditions. The stratification increase in the upper tributaries during the transition period was much larger than that during the typical wet and dry seasons.

As the PRE is a bell-shaped estuary, it exhibited an increase of tidal range and tidal current speed in response to the sea-level rise. This increase was amplified toward the upstream region, with the greatest increase occurring in the upper tributaries. The increase of tidal current in the surface layer was greater than that in the bottom layer. From our study, the change of VET caused by sea-level rise is not large, and was only evident in the upper LDB during the wet season, where VET increased by approximately two days in response to the $1.0 \mathrm{~m}$ sea-level rise scenario. Therefore, unlike in Chesapeake Bay, our model suggested that sea-level rise will have only a minor impact on the vertical transport of dissolved oxygen in the PRE.

The upstream transport processes for dissolved substances coming from the ocean were strengthened in the sea-level rise scenarios during the typical wet season, while these were weakened during the dry season. In the winter dry season, the circulation pattern in the PRE was more like coastal circulation rather than a classical two-layer gravitational circulation pattern. Moreover, an additional 20 days was needed for the upstream transport of dissolved substances from the estuary mouth to upper LDB during the dry season in comparison with the wet season.

Downstream transport was slowed in the sea-level rise cases in both wet and dry seasons. The residence time during the dry season (35 days) was longer than that during the wet season (6 days). For a sea-level rise of $1 \mathrm{~m}$, the dry season residence time increased 8.5 days. This meant that the fluvial input will remain in the PRE for a longer time after a rise in sea-level, which will affect the biogeochemical processes by increasing the retention time of dissolved substances.

\section{Acknowledgments}

This research was generously funded by the National Natural Science Foundation of China (Grant Nos. 41976014, 51761135021, 41406005, 41666001), the Key Research Program of Frontier Sciences, Chinese Academy Sciences (No. QYZDJ-SSWDQC022), and the Open Research Fund of State Key Laboratory of 
Estuarine and Coastal Research (No. SKLEC-KF201604). This paper is ContributionNo. 3856 of Virginia Institute of Marine Science, William \& Mary. We thank the editor and three anonymous reviewers for their comments that helped to improve the manuscript.

\section{References}

Ali, A., 1995. A numerical investigation into the back water effect on flood water in the Meghna River in Bangladesh due to the south-west monsoon wind. Estuar. Coast. Shelf Sci. 41 (6), 689-704.

Bhuiyan, M.J.A.N., Dutta, D., 2012. Assessing impacts of sea level rise on river salinity in the Gorai River network, Bangladesh. Estuarine, Coastal and Shelf Science 96, 219-227.

Chen, W.B., Liu, W.C., Hsu, M.H., 2015. Modeling assessment of a saltwater intrusion and a transport time scale response to sea-level rise in a tidal estuary. Environmental. Fluid Mechanics 15, 491-514.

Chen, W., Chen, K., Kuang, C., Zhu, D.Z., He, L.L., Mao, X.D., Liang, H., Song, H., 2016. Influence of sea level rise on saline water intrusion in the Yangtze River Estuary, China. Appl. Ocean Res. 54, 12-25.

Cheng, Z.L., 2001. Decadal variation of hydrological status in stream network area and the eight outlets of Pearl River Delta. Acta Scientiarum Naturalium Universitatis Sunyatseni 40 (Suppl. 2), 29-31 (in Chinese).

Chua, V.P., Xu, M., 2014. Impacts of sea-level rise on estuarine circulation: an idealized estuary and San Francisco Bay. J. Mar. Syst. 139, 58-67.

Church, J.A., White, N.J., 2006. A 20th century acceleration in global sea-level rise. Geophys. Res. Lett. 33, L01602.

Cui, Y.S., Wu, J.X., Ren, J., Xu, J., 2018. Physical dynamics structures and oxygen budget of summer hypoxia in the Pearl River Estuary. Limnol. Oceanogr. 64, 131-148.

Deleersnijder, E., Campin, J., Delhez, E., 2001. The concept of age in marine modeling: I. Theory and preliminary model results. J. Mar. Syst 28, 229-267.

Dong, L., Su, J., Li, Y., Xia, X., Guan, W., 2006. Physical Processes and Sediment Dynamics in the Pearl River. The Environment in Asia Pacific Harbours, Springer Netherlands.

Du, J., Shen, J., Zhang, Y.J., Ye, F., Liu, Z., Wang, Z., Wang, Y.P., Yu, X., Sisson, M., Wang, H., 2018. Tidal response to sea-level rise in different types of estuaries: the importance of length, bathymetry, and geometry. Geophys. Res. Lett. 45 (1), 227-235.

Egbert, G.D., Erofeeva, S.Y., 2002. Efficient inverse modeling of barotropic ocean tides. J. Atmos. Ocean. Technol. 19 (2), 183-204.

Garcon, V.C., Stolzenbach, K.D., Anderson, D.M., 1986. Tidal flushing of an estuarine embayment subject to recurrent dinoflagellate blooms. Estuaries 9 (3), 179-187. https://doi.org/10.2307/1352129.

Gong, W.P., Shen, J., Hong, B., 2009. The influence of wind on the water age in the tidal Rappahannock River. Mar. Environ. Res. 68, 203-216.

Gong, W.P., Maa, J.P., Hong, B., Shen, J., 2014. Salt transport during a dry season in the Modalmen Estuary, Pearl River Delta, China. Ocean \& Coastal Management 100 139-150.

Gong, W.P., Lin, Z.Y., Chen, Y.Z., Chen, Z.Y., Zhang, H., 2018. Effect of winds and waves on salt intrusion in the Pearl River estuary. Ocean Sci 14, 139-159.

Guan, S., Lin, Y., Liu, Z., 2017. Modeling approach to assess the effects of sea level rise on saltwater intrusion in Modaomen Estuary. Pearl River 38 (8), 1-6.

Grabemann, H., Grabemann, I., Herbers, D., Muller, A., 2001. Effects of a specific climate scenario on the hydrography and transport of conservative substances in the Weser estuary, Germany: a case study. Climate Res 18, 77-87.

Hagy, J.D., Boynton, W.R., Keefe, C.W., Wood, K.V., 2004. Hypoxia in Chesapeake Bay, 1950-2001: long-term change in relation to nutrient loading and river flow. Estuaries 27 (4), 634-658.

Hamrick, J.M., Wu, T.S., 1997. Computational design and optimization of the EFDC/ HEM3D surface water hydrodynamic and eutrophication models. In: Delich, G., Wheeler, M.F. (Eds.), Next Generation Environmental Models and Computational Methods. Society for Industrial and Applied Mathematics, Pennsylvania, pp. 143-161.

Hilton, T.W., Najjar, G.G., Zhong, L., Li, M., 2008. Is there a signal of sea-level rise in Chesapeake Bay salinity? J. Geophys. Res. 113, C09002. https://doi.org/10.1029/ 2007JC004247.

Hong, B., Shen, J., 2012. Responses of estuarine salinity and transport processes to potential future sea-level rise in the Chesapeake Bay. Estuar. Coast. Shelf Sci. 104-105, $33-45$.

Hong, B., Shen, J., 2013. Linking dynamics of transport timescale and variations of hypoxia in the Chesapeake Bay. J. Geophys. Res.-Oceans 118, 1-13.

Hong, B., Gong, W.P., Peng, S., Xie, Q., Wang, D., Li, H., Xu, H., 2016. Characteristics of vertical exchange process in the Pearl River Estuary (PRE). Aquatic Ecosystem Health \& Management 19 (3), 286-295.

Hong, B., Shen, J., H, Xu, 2018. Upriver transport of dissolved substances in an estuary and sub-estuary system of the lower James River, Chesapeake Bay. Frontiers of Earth Science 12 (3), 583-599.

IPCC, 2013: Climate change 2013: the physical science basis. Contribution of Working Groups I to the Fifth Assessment Report of the Intergovernmental Panel on Climate Change. Chapter 13, Sea Level Change, Coordinating Lead Authors: John A. Church, Peter U., Clark. Cambridge University Press, Cambridge, United Kingdom and New York, NY, USA.

Ji, X., Sheng, J., Tang, L., Liu, D., Yang, X., 2011. Process study of dry-season circulation in the Pearl River Estuary and adjacent coastal waters using a triple-nested coastal circulation model. Atmosphere-Ocean 49 (2), 138-162.

Lai, Z., Ma, R., Gao, G., Chen, C., Beardsley, R.C., 2015. Impact of multichannel river network on the plume dynamics in the Pearl River estuary. J. Geophysical Research:
Oceans 120, 5766-5789. https://doi.org/10.1002/2014JC010490.

Lai, Z., Ma, R., Huang, M., Chen, C., Chen, Y., Xie, C., Beardsley, R.C, 2016. Downwelling wind, tides, and estuarine plume dynamics. J. Geophys. Res.-Oceans 121, 4245-4263.

Lai, W., Pan, J., Devlin, A.T., 2018. Impact of tides and winds on estuarine circulation in the Pearl River Estuary. Cont. Shelf Res. 168, 68-82.

Lehrter, J.C., 2008. Regulation of eutrophication susceptibility in oligohaline regions of a northern Gulf of Mexico estuary, Mobile Bay, Alabama. Mar. Pollut. Bull. 56 (8), $1446-1460$.

Lin, Z.Y., Zhang, H., Lin, H., Gong, W.P., 2019. Intraseasonal and interannual variabilities of saltwater intrusion during dry seasons and the associated driving forcings in a partially mixed estuary. Cont. Shelf Res. 174, 95-107.

Lu, Z.M., Gan, J.P., 2015. Controls of seasonal variability of phytoplankton blooms in the Pearl River Estuary. Deep-Sea Res. 117, 86-96.

MacCready, P., Geyer, W.R., 2010. Advances in estuarine physics. Annu. Rev. Mar. Sci. 2, 35-58.

Mao, Q., Shi, P., Yin, K., Gan, J., Qi, Y., 2004. Tides and tidal currents in the Pearl River estuary. Cont. Shelf Res. 24, 1797-1808.

Murphy, R., Kemp, W., Ball, W., 2011. Long-term trends in Chesapeake Bay seasonal hypoxia, stratification, and nutrient loading. Estuar. Coasts 34, 1293-1309.

Najjar, R.G., Pyke, C.R., Adams, M.B., Breitburg, D., Hershner, C., Kemp, M., Howarth, R., Mulholland, M.R., Paolisso, M., Secor, D., Sellner, K., Wardrop, D., Wood, R., 2010. Potential climate-change impacts on the Chesapeake Bay. Estuar. Coast. Shelf Sci. 86, 1-20. https://doi.org/10.1016/j.ecss.2009.09.026.

Nicholls, R.J., Cazenave, A., 2010. Sea-level rise and its impact on coastal zone. Science 328 (5985), 1517-1520.

Pickering, M.D., Horsburgh, K.J., Blundell, J.R., Hirschi, J.J.M., Nicholls, R.J., Verlaan, M., 2017. The impact of future sea-level rise on the global tides. Cont. Shelf Res. 142, 50-68.

PRWRC (Pearl River Water Resource Conservancy), 1991. The Pearl River Records 1 (Zhujiang Zhi). Guangdong Science \& Technology Press, Guangzhou, China (in Chinese).

Qiu, C., Zhu, J., 2015. Assessing the influence of sea level rise on salt transport processes and estuarine circulation in the Changjiang River Estuary. J. Coast. Res. 31 (3), 661-670.

Rice, K.C., Hong, B., Shen, J., 2012. Assessment of salinity intrusion in the James and Chickahominy rivers as a result of simulated sea-level rise in Chesapeake Bay, East Coast, United States. Journal of Environmental Management 111, 61-69.

Scully, M.E., 2010. Wind modulation of dissolved oxygen in Chesapeake Bay. Estuar. Coasts 33, 1164-1175.

Shen, J., Haas, L., 2004. Calculating age and residence time in the tidal York River using three-dimensional model experiments. Estuar. Coast. Shelf Sci. 61 (3), 449-461.

Sinha, P., Rao, Y., Dube, S., Murty, T., 1997. Effect of sea level rise on tidal circulation in the Hooghly estuary, Bay of Bengal. Mar. Geod. 20, 341-366.

Valentim, J.M., Vaz, N., Silva, H., Duarte, B., Cacador, I., Dias, J.M., 2013a. Tagus estuary and Ria de Aveiro salt marsh dynamics and the impact of sea level rise. Esutarine, Coastal and Shelf Science 130, 138-151.

Valentim, J.M., Vaz, L., Vaz, N., Silva, H., Duarte, B., Caçador, I., Dias, J.M., 2013b. Sea level rise impact in residual circulation in Tagus estuary and Ria de Aveiro lagoon. Journal of Coastal Research, Special Issue No. 65, 1981-1986.

Wang, B., Hu, J.T., Li, S.Y., Liu, D.H., 2017. A numerical analysis of biogeochemical controls with physical modulation on hypoxia during summer in the Pearl River estuary. Biogeosciences 14, 2979-2999.

Wei, X., Zhan, H.G., Ni, P.T., Cai, S.Q., 2016. A model study of the effects of river discharges and winds on hypoxia in summer in the Pearl River Estuary. Mar. Pollut. Bull. 113, 414-427.

Wilson, R.E., Swanson, R.L., Crowley, H.A., 2008. Perspectives on long-term variations in hypoxic conditions in western Long Island Sound. J. Geophys. Res. 113, C12011. https://doi.org/10.1029/2007JC004693.

Wong, L., Chen, J., Xue, H., Dong, L., Su, J., Heinke, G., 2003. A model study of the circulation in the Pearl River estuary (PRE) and its adjacent coastal waters: 1. Simulations and comparison with observations. Journal of Geophysical Research 108(C5), 3156, doi:https://doi.org/10.1029/2002JC001451.

Xia, M., Xie, L., Pietrafesa, L.J., Whitney, M.M., 2011. The ideal response of a Gulf of Mexico estuary plume to wind forcing: its connection with salt flux and a Lagrangian view. Journal of Geophysical Research 116, C08035. In: Doi:10/1029/ 2010JC006689.

Xiao, H., Huang, W., Johnson, E., Lou, S., Wan, W., 2014. Effects of sea level rise on salinity intrusion in St. Marks River Estuary, Florida, U.S.A. J. Coast. Res. 98, 89-96.

Xu, J., Li, Y., Chen, T., 1981. Features of salt water intrusion and salt wedge movements in Lingding Yang. Tropical Geography 3 (1), 36-44.

Ye, L., Preiffer, K.D., 1990. Studies of 2D \& 3D numerical simulation of Kelvin tide wave in Nei Lingdingyang at Pearl River Estuary. Ocean Eng. 8 (4), 33-44.

Yuan, R., Zhu, J., Wang, B., 2015. Impact of sea-level rise on saltwater intrusion in the Pearl River Estuary. J. Coast. Res. 31 (2), 477-487.

Zhao, H., 1990. The Evolution of the Pearl River Estuary, 357 pp. China Ocean Press, Beijing.

Zhen, S., Guan, W.B., Cai, S.Q., Wei, X., Huang, D.J., 2014. A model study of the effects of river discharges and interannual variation of winds on the plume front in winter in Pearl River Estuary. Cont. Shelf Res. 73, 31-40.

Zhai, W., Dai, M., Cai, W.-J., Wang, Y., Wang, Z., 2005. High partial pressure of CO2 and its maintaining mechanism in a subtropical estuary: the Pearl River estuary. China. Mar. Chem 93, 21-32.

Zhong, L., Li, M., Foreman, M.G.G., 2008. Resonance and sea level variability in Chesapeake Bay. Cont. Shelf Res. 28, 2565-2573.

Zhou, W., Luo, L., Xu, H., Wang, D., 2012. Saltwater intrusion in the Pearl River Estuary during winter. Aquat. Ecosyst. Health Management 15 (1), 70-80. 